\title{
LOS ÁMBITOS DE APLICACIÓN DEL PRINCIPIO DE PRESUNCIÓN DE INOCENCIA
}

\section{José María SOBERANES DÍEZ}

En el contexto de la llamada reforma judicial que, entre otras cosas, incorpora formalmente al texto constitucional el principio de presunción de inocencia, consideramos conveniente comentar la sentencia dictada por la Segunda Sala al resolver el amparo en revisión $89 / 2007,{ }^{1}$ por ser una de las pocas sentencias mexicanas en la que se definen los alcances de un derecho fundamental, estableciendo que no se limita al ámbito del derecho penal.

\section{ANTECEDENTES}

En octubre de 2004 el juez segundo de distrito en el estado de Guanajuato dictó auto de formal prisión a un policía federal por su probable responsabilidad en la comisión del delito de cohecho previsto en el artículo 222, fracción I, del Código Penal Federal.

A raíz de dicha resolución, la Comisión del Servicio Civil de Carrera de la Policía Federal Preventiva inició un procedimiento administrativo de responsabilidad en contra del elemento policial por infringir el requisito de permanencia previsto en el artículo 14, fracción II, de la Ley de la Policía Federal Preventiva, consistente en "no estar sujeto a proceso penal". ${ }^{2}$ El procedimiento concluyó con una resolución el 20 de mayo de 2005 en la que se determinó que el policía era responsable de haber in-

1 Sentencia dictada el 21 de marzo de 2007, por unanimidad de cinco votos. Ministro ponente: Genaro David Góngora Pimentel, secretario: Marat Paredes Montiel.

2 El artículo señala textualmente: "Artículo 14. Para ingresar o permanecer en la Policía Federal Preventiva se requiere... II. Ser de notoria buena conducta, no haber sido condenado por sentencia irrevocable por delito doloso, ni estar sujeto a proceso penal...". 
cumplido el requisito de permanencia mencionado, decretando su baja administrativa.

En contra de dicha determinación, el miembro de la corporación policiaca promovió juicio de amparo, destacando como acto reclamado el artículo 14, fracción II, de la Ley de la Policía Federal Preventiva. El juez de distrito en Guanajuato que conoció del asunto sobreseyó el juicio al considerar que no se habían expuesto razonamientos lógico-jurídicos que demostraran su inconstitucionalidad.

El policía interpuso recurso de revisión. Correspondió conocer de éste al Tribunal Colegiado del Decimosexto Circuito, quien resolvió levantar el sobreseimiento y enviar el asunto a la Suprema Corte de Justicia de la Nación para que resolviera en definitiva sobre el planteamiento de inconstitucionalidad.

\section{MATERIA DEL CASO}

El primer obstáculo al que se enfrentó la Sala fue delimitar la materia del asunto, pues los planteamientos del policía quejoso no eran muy claros, pues únicamente reproducían los artículos 5o., 13 y 14 constitucionales, haciendo algunas manifestaciones aisladas.

En una decisión que consideramos acertada, por dar preeminencia a la delimitación sobre el contenido y alcances de derechos fundamentales sobre formalismos argumentativos, la Sala interpretó que el quejoso, al afirmar que se le está privando del derecho a ser policía sin que exista una sentencia que lo condene, se refiere al principio de presunción de inocencia, según el cual, nadie puede ser privado de sus derechos sino hasta que exista una sentencia firme que lo condene. ${ }^{3}$ De esta forma, procedió a examinar si el artículo 14, fracción II, de la Ley de la Policía Federal Preventiva, en cuanto dice "no estar sujeto a proceso penal" transgredía el principio de presunción de inocencia.

3 De estas consideraciones surgió la tesis 2a. XXXVI/2007, de rubro "CONCEPTOS DE VIOLACIÓN. PARA QUE SE ANALICEN ES INNECESARIO QUE SE MENCIONE EL NOMBRE DEL PRINCIPIO CONSTITUCIONAL QUE SE ESTIMA VIOLADO”, publicada en el Semanario Judicial de la Federación y su Gaceta, Novena Época, t. XXV, mayo de 2007, p. 1183. 


\section{LA SENTENCIA DE LA SEGUNDA SALA}

A diferencia de otras sentencias de la Suprema Corte, la que comentamos es breve. No busca repetir argumentos ni transcribir diversas tesis de jurisprudencia. Más bien parece que prefiere concertar los argumentos y ser clara, como en otras jurisdicciones.

En primer término examina si el artículo 123, apartado B, fracción $\mathrm{XIII},{ }^{4}$ al señalar que las leyes deben establecer los requisitos de permanencia o ingreso en las instituciones policiacas establece un campo libre al legislador en este aspecto, tomado en cuenta que fue intención del Constituyente establecer mecanismos que hicieran eficaz el interés general de depurar estas corporaciones.

La sentencia contesta negativamente. Sostiene, en primer lugar, que en una ponderación entre derechos fundamentales y el interés general de contar con policías honestos, deben prevalecer los derechos, pues "no hay en el sistema constitucional mexicano un interés de mayor generalidad y de mayor envergadura que el respeto a las garantías individuales, en específico al núcleo esencial que esta tutela".

En este sentido afirma que el hecho de que se intente depurar y profesionalizar las instituciones policiales no puede entenderse como una libertad absoluta e ilimitada de configuración legislativa, pues las leyes respectivas deben respetar las garantías individuales de los miembros de

4 "XIII. Los militares, marinos, personal del servicio exterior, agentes del Ministerio Público y los miembros de las instituciones policiales, se regirán por sus propias leyes.

El Estado proporcionará a los miembros en el activo del Ejército, Fuerza Aérea y Armada, las prestaciones a que se refiere el inciso f) de la fracción XI de este apartado, en términos similares y a través del organismo encargado de la seguridad social de los componentes de dichas instituciones; y

Los miembros de las instituciones policiales de los municipios, entidades federativas, del Distrito Federal, así como de la Federación, podrán ser removidos de su cargo si no cumplen con los requisitos que las leyes vigentes en el momento de la remoción señalen para permanecer en dichas instituciones, sin que proceda su reinstalación o restitución, cualquiera que sea el juicio o medio de defensa para combatir la remoción y, en su caso, sólo procederá la indemnización. La remoción de los demás servidores públicos a que se refiere la presente fracción, se regirá por lo que dispongan los preceptos legales aplicables". (Texto vigente al momento de dictar la sentencia; sin embargo, fue modificada la fracción XIII mediante decreto publicado en el Diario Oficial de la Federación del 18 de junio de 2008). 
las instituciones policiales. Sin embargo, sostiene, pueden restringirlas de forma proporcional, matizando el la afirmación dworkiniana del absolutismo de los derechos fundamentales.

No obstante que sostiene que debe hacerse un juicio de proporcionalidad para determinar si la interferencia legislativa al mencionado derecho fundamental era constitucional, no sigue formalmente test de razonabilidad anunciado, como ha hecho en otras ocasiones, ${ }^{5}$ aunque deje entrever un análisis del subprincipio de idoneidad del mencionado test, diciendo que no se vulneraría ese principio en caso de la aplicación de una medida cautelar a los policías sujetos a proceso penal.

Así pues, procede a valorar si la norma reclamada se respeta el principio de presunción de inocencia. El análisis de constitucionalidad parte de la sentencia dictada por el Pleno al resolver el amparo en revisión 1293/ 2000 , el 15 de agosto de 2002, en donde reconoció que el derecho a la presunción de inocencia es tutelado implícitamente por la Constitución. ${ }^{6}$

A partir de esto, la Sala procedió a analizar los ámbitos de aplicación de este principio. Al respecto consideró que la presunción de inocencia, además de ser un principio informador del ordenamiento procesal es, ante todo, un derecho fundamental que la Constitución reconoce y garantiza a todos, pues "con su operancia se garantiza la protección de otros derechos fundamentales que podrían resultar vulnerados como conse-

5 El test de proporcionalidad ha sido utilizado por la Suprema Corte sobre todo en el análisis del principio de igualdad. La Primera Sala, por ejemplo, determinó que debe utilizarse este test para valorar los planteamientos de igualdad en la jurisprudencia 1a./J. 55/2006, de rubro "IGUALDAD. CRITERIOS PARA DETERMINAR SI EL LEGISLAdOR RESPETA ESE PRINCIPIO CONSTITUCIONAL" (publicada en el Semanario Judicial de la Federación y su Gaceta, Novena Época, t. XXIV, septiembre de 2006, p. 75). Lo mismo hizo la Segunda Sala respecto a la igualdad tributaria en la jurisprudencia 2a./J. 31/2007 de rubro "EQUIDAD TRIBUTARIA. CRITERIOS PARA DETERMINAR SI EL LEGISLADOR RESPETA DICHO PRINCIPIO CONSTITUCIONAL" (publicada en el Semanario Judicial de la Federación y su Gaceta, Novena Época, t. XXV, marzo de 2007, p. 334). Asimismo, el Tribunal Pleno utilizó este test al resolver los amparos promovidos por militares dados de baja por ser portadores de VIH, sobre todo en el amparo en revisión 2146/2005, respecto del cual puede consultarse Silva García, Fernando, "VIH y militares (criterios jurisprudenciales de la SCJN)", Cuestiones Constitucionales. Revista Mexicana de Derecho Constitucional, México, num. 18, enero-junio de 2008, pp. 309-325.

6 De dicho asunto surgió la tesis P. XXXV/2002, de rubro "PRESUNCIÓN DE INOCENCIA. EL PRINCIPIO RELATIVO SE CONTIENE DE MANERA IMPLÍCITA EN LA CONSTITUCIÓN FEDERAL", publicada en el Semanario Judicial de la Federación y su Gaceta, Novena Época, t. XVI, agosto de 2002, p. 14. 
cuencia de actuaciones penales o disciplinarias irregulares, como lo son la dignidad humana, la libertad, la honra y el buen nombre". Por ello, afirmó que

el principio de presunción de inocencia opera en las situaciones extraprocesales y constituye el derecho a recibir la consideración y el trato de no autor o no partícipe en hechos de carácter delictivo o análogos a éstos y determina, por ende, el derecho a que no se apliquen las consecuencias o los efectos jurídicos anudados a hechos de tal naturaleza en las relaciones jurídicas de todo tipo.

De estos razonamientos surgió la siguiente tesis:

PRESUNCIÓN DE INOCENCIA. AlCANCES DE ESE PRINCIPIO CONSTITUCIONAL. El principio de presunción de inocencia que en materia procesal penal impone la obligación de arrojar la carga de la prueba al acusador, es un derecho fundamental que la Constitución Política de los Estados Unidos Mexicanos reconoce y garantiza en general, cuyo alcance trasciende la órbita del debido proceso, pues con su aplicación se garantiza la protección de otros derechos fundamentales como son la dignidad humana, la libertad, la honra y el buen nombre, que podrían resultar vulnerados por actuaciones penales o disciplinarias irregulares. En consecuencia, este principio opera también en las situaciones extraprocesales y constituye el derecho a recibir la consideración y el trato de "no autor o no partícipe" en un hecho de carácter delictivo o en otro tipo de infracciones mientras no se demuestre la culpabilidad; por ende, otorga el derecho a que no se apliquen las consecuencias a los efectos jurídicos privativos vinculados a tales hechos, en cualquier materia. ${ }^{7}$

En otras jurisdicciones ya se habían hecho interpretaciones semejantes a la de la Sala. El Tribunal Constitucional español sostuvo que "la presunción de inocencia no puede entenderse limitada al estricto campo del enjuiciamiento de las conductas penales, sino extensiva a cualquier resolución que pueda limitar los derechos subjetivos". ${ }^{8}$

En el ámbito internacional, la Corte Interamericana de Derechos $\mathrm{Hu}-$ manos sostuvo que a pesar de que el artículo 80. del Pacto de San José, que contiene las garantías del debido proceso (entre las que se encuentra

7 Tesis 2a. XXXV/2007, publicada en el Semanario Judicial de la Federación y su Gaceta, Novena Época, t. XXV, mayo de 2007, p. 1186.

8 Sentencia S. 13/82, del 1o. de abril de 1982. 
la presunción de inocencia) no especifica los ámbitos de aplicación de dichas garantías, es aplicable todos los órdenes:

el elenco de garantías mínimas establecido en ese precepto se aplica también a esos órdenes [civil, laboral, fiscal o de cualquier otro carácter, había dicho previamente] y, por ende, en ese tipo de materias el individuo tiene también el derecho, en general, al debido proceso que se aplica en materia penal. ${ }^{9}$

Por su parte, la Corte Constitucional colombiana sostuvo que "la presunción de inocencia es la institución jurídica más importante con las que cuentan los particulares para resguardarse de la posible arbitrariedad de las actuaciones del Estado. Como consecuencia, no sólo es un principio del debido proceso, sino una garantía de la dignidad humana". ${ }^{10}$

También la Suprema Corte de Justicia de la República Dominicana, sostuvo que la presunción de inocencia opera "no tan sólo en los casos de procedimientos judiciales, sino ante cualquier actuación contraria a un derecho consagrado, siendo el Estado compromisario de tutelar esas garantías". ${ }^{11}$

El caso más parecido a éste se presentó en Perú, en donde una ley establecía que los policías nacionales sujetos a procesos penales debían ser cesados. El Tribunal Constitucional de aquella nación señaló:

Este Colegiado considera que así entendida la posibilidad de aplicar tal sanción disciplinaria, es violatoria del principio de presunción de inocencia, pues resulta claro que, con la sola imputación de un delito, tal presunción no pierde sus efectos, sino hasta que exista una declaración judicial de responsabilidad penal. Ello no quiere decir que se permita que el efectivo policial sujeto a un proceso penal continúe en situación de actividad, pues es perfectamente lícito, si es que se compromete a las tareas constitucionalmente reservadas a la Policía Nacional del Perú, que éste sea pasado a la situación de disponibilidad, durante todo el lapso que dure la realización de dicho proceso judicial. ${ }^{12}$

Una vez sentado que la presunción de inocencia obliga a que las personas no pierdan sus derechos sin ser declaradas culpables por una sennúm. 70.

9 Caso del Tribunal Constitucional vs. Perú, sentencia del 31 de enero de 2001,

10 Sentencia C-252/2001 del 28 de febrero de 2001.

11 Resolución 1920-2003, del 13 de noviembre del 2003.

12 Sentencia dictada en el expediente 2050-2002-AA/TC. 
tencia, y tomando en cuenta que el artículo 14, fracción II, de la Ley de la Policía Federal Preventiva establece que el solo hecho de estar sujeto a proceso penal es suficiente para que el quejoso se vea menoscabado en su derecho a ser policía, parecería evidente que el siguiente paso sería la declaración de inconstitucionalidad del precepto. Sin embargo, la sentencia da un giro inesperado.

La Sala valora que el artículo 14 de la Ley de la Policía Federal Preventiva regula indistintamente tanto los requisitos de ingreso como de permanencia en la institución policial, dándose a la tarea de determinar si el requisito de no estar sujeto a proceso penal es una exigencia de ingreso o de permanencia.

Para salvar la constitucionalidad de la norma, la Corte hace una interpretación conforme, señalando que si se considera un requisito de ingreso y no de permanencia, la exigencia de no estar sujeto a proceso penal, es constitucional en tanto no conlleva la pérdida de un derecho, sino simplemente de la expectativa de derecho a ser policía. De estas consideraciones surgió la siguiente tesis:

Policía Federal PreVentiva. El Requisito de no Sujeción a PROCESO PENAL, PREVISTO EN EL ARTíCULO 14, FRACCIÓN II, DE LA LEY RELATIVA, ES DE INGRESO Y NO DE PERMANENCIA PARA LOS MIEMBROS DE ESA CORPORACIÓN. En el proceso legislativo que culminó con la expedición de la Ley de la Policía Federal Preventiva se señaló que los requisitos enunciados en el citado precepto deben considerarse como de ingreso o de permanencia, pues se usó la conjunción disyuntiva "o" y no la "y". En ese tenor, el requisito consistente en no estar sujeto a proceso penal, previsto en la fracción II del artículo 14 de la Ley citada, conforme al principio de presunción de inocencia, debe interpretarse como referido sólo al ingreso y no a la permanencia, pues en este supuesto, si no está demostrada la culpabilidad del interesado, no podría realizarse ningún acto de privación en su contra. Además implicaría prejuzgar sobre la responsabilidad penal de los miembros de la Policía Federal Preventiva, sin sentencia condenatoria previa, en clara violación al mencionado principio de presunción de inocencia. ${ }^{13}$

Interpretado de esta forma, el artículo 14 de la Ley de la Policía Federal Preventiva no es contrario al principio de presunción de inocencia.

13 Tesis 2a. XLIII/2007, publicada en el Semanario Judicial de la Federación y su Gaceta, Novena Época, t. XXV, mayo de 2007, p. 1185. 
Pero igualmente, esa interpretación llevó a que el procedimiento administrativo de responsabilidad que dio origen al asunto estuviera fundado en el incumplimiento de un requisito de permanencia que no lo es propiamente. Por ello, la Corte determinó que el procedimiento administrativo era contrario al principio de legalidad, por su incorrecta fundamentación. En consecuencia la Segunda Sala concedió el amparo al quejoso únicamente respecto al acto de aplicación, pero sin declarar inconstitucional la Ley impugnada. 